\title{
ENGAJAMENTO CIDADÃO E PROCESSOS DECISÓRIOS: ABORDAGEM A PARTIR DO FEDERALISMO BRASILEIRO
}

\author{
CITIZEN ENGAGEMENT AND DECISION-MAKING \\ PROCESSES: APPROACH FROM THE BRAZILIAN \\ FEDERALISM
}

\author{
Fernanda Gabriela Gandra Pimenta Magalhães ${ }^{1}$ \\ Wesley de Almeida Mendes ${ }^{1}$ \\ Marco Aurélio Marques Ferreira ${ }^{1}$ \\ Edson Arlindo Silva ${ }^{2}$
} Recebido em: 04/07/2016
Aceito em: 04/08/2016
wesleyadm@live.com
Resumo: Este é um artigo de metodologia teórica que tem por objetivo apresentar, com base na revisão da literatura que abrange a temática da evolução do Estado, federalismo e a democracia no Brasil e participação popular, debates teóricos quanto ao federalismo, engajamento cidadão e participação popular, colocando em destaque o papel do orçamento participativo. Constatou-se que esse contexto possibilita participação, assim como o controle e aplicação de políticas públicas, destacando o orçamento participativo como importante instrumento de minimização de desigualdades e desequilíbrio de acesso ao poder decisório. Por fim notou-se que o federalismo ainda não oferece garantias para efetivação da participação, sendo necessário pôr em prática meios que viabilizem a democratização do processo de formulação e controle de políticas públicas.

Palavras-chave: Federalismo. Democracia. Participação Popular. Orçamento Participativo.

Abstract: This is a theoretical methodology article, aims to present, based on the literature review covering the theme of the evolution of the state, federalism and democracy in Brazil and popular participation, theoretical debates about federalism, citizen engagement and public participation, by highlighting the role of participatory budgeting. It was found that this context allows participation, as well as control and implementation of public policies, highlighting participatory budgeting as an important tool to minimize inequalities and imbalance of access to decision-making power. Finally it was noted that federalism does not offer guarantees for effective participation, being necessary to implement means that enable the democratization of the process of formulation and control of public policies.

Keywords: Federalism. Democracy. Popular Participation. Participatory Budget.

\footnotetext{
${ }^{1}$ Universidade Federal de Viçosa - UFV - Viçosa - Minas Gerais - Brasil.

${ }^{2}$ Universidade Federal de Uberlândia - UFU - Uberlândia - Minas Gerais - Brasil.
} 


\section{INTRODUÇÃO}

Ainda que sejam muitas as teorias que discorrem sobre a origem e justificação do Estado, pode-se afirmar de forma sucinta que este é obra da inteligência e desejo do grupo social ou de seus representantes, constituindo-se como uma organização político-jurídica de uma sociedade cuja finalidade reside na consecução do bem público (AZAMBUJA, 2008), se formando e evoluindo por meio das necessidades sociais.

Os modelos de Estado vistos ao longo da história pouco possibilitavam a participação do grupo social nas decisões sobre a consecução desse bem público, fazendo com que o papel do povo se tornasse pouco (ou nada) relevante nas decisões políticas, impossibilitando assim o exercício da democracia. A autocracia, vista nos modelos monárquicos e ditatoriais, retirava das decisões públicas a vontade popular.

No Brasil, cuja formação foi grandemente marcada por períodos e regimes não democráticos e por arranjos históricos de exclusão, devem ser considerados esses traços marcantes na instauração do regime democrático e observado em sua consolidação.

Com a promulgação da Constituição da República Federativa do Brasil em 1988, após o período ditatorial, são apresentadas garantias de democracia e participação popular, bem como da descentralização político-administrativa do novo período republicano federativo brasileiro, visando assim sanar gargalos deixados pela formação histórica do Brasil. Como destacado por Souza (2001), no Brasil o processo de redemocratização e a descentralização caminharam juntos.

Assim, novas configurações institucionais se formam com a consolidação do Estado Democrático de Direito no Brasil, institucionalizando novos mecanismos para a legitimação dos cidadãos para o Controle Social nas diversas esferas da ação do Estado (LOPES et al, 2013).

Nesse sentido, estudos sobre a participação popular têm se avolumado nas academias brasileiras, como as pesquisas de Kerbauy (2001), Avritzer (2003), e Carneiro (2007), conduzindo análises que buscam retratar de que forma estas iniciativas têm se consolidado no território nacional. Em seu estudo sobre federalismo, descentralização e democracia, Kerbauy (2001) focaliza as possibilidades de arranjos organizativos e participativos encontrados pelos municípios brasileiros, que podem levar a estilos administrativos diferenciados. Avritzer (2003), por sua vez, destaca que o objetivo do projeto, que deu origem ao livro em questão é ampliar o escopo de análise sobre o orçamento participativo, incluindo nessa discussão um conjunto de novas experiências, seja no campo do papel do governo e da participação. Carneiro (2007) realiza um estudo teórico, analisando a teoria da democracia participativa à luz do princípio da soberania popular.

Retomando algumas dessas análises e verificando a importância atribuída a esses mecanismos de consolidação da democracia deliberativa, torna-se importante proceder a uma reflexão que relacione o federalismo enquanto um condicionante de efetivação da democracia, no sentido de entender como o modelo federativo brasileiro pode estimular a participação popular, através da maior descentralização político-administrativa.

Assim, o objetivo central deste trabalho é analisar de que forma o federalismo pode influenciar ou propiciar a participação popular, colocando em pauta uma das instâncias já existentes,

Estudos do CEPE [ISSN 1982-6729]. Santa Cruz do Sul, n. 43, p.153-166, jan./jun. 2016. https://online.unisc.br/seer/index.php/cepe/index 
os orçamentos participativos, a experiência de participação local mais discutida no Brasil e que se refere à uma concepção de construção e implementação de um processo coletivo e público de discussão e formulação do orçamento municipal (BALESTERO, 2011; AVRITZER, 2003). Destaca-se ainda a importância do fortalecimento do poder local/municipal como instrumento de concretização da participação popular.

Para tais esclarecimentos pretendidos, a segunda seção deste estudo perpassa a evolução histórica do Estado, contextualizando assim os movimentos de formação do Estado até o Estado Democrático de Direito Brasileiro e a participação popular nas tomadas de decisões. A terceira seção faz uma revisão de literatura sobre o federalismo e a democracia no Brasil, analisando as origens do modelo federativo, o modelo federativo brasileiro em si, a constituição brasileira e a descentralização político-administrativa. O tópico seguinte trata da participação popular, trazendo no último tópico o exemplo dos orçamentos participativos, de forma a atender ao objetivo inicial de avaliar como o federalismo brasileiro pode propiciar a participação popular, chegando assim às conclusões, discutindo os argumentos encontrados na literatura analisada.

O presente artigo consiste em um ensaio teórico que tem por objetivo apresentar, com base na revisão da literatura, debates teóricos quanto ao engajamento cidadão e participação popular, colocando em destaque o papel do orçamento participativo.

Do ponto de vista dos objetivos, o estudo se caracteriza como pesquisa exploratória, que tem por finalidade uma análise inicial do assunto para, posteriormente, criar condições para estudos empíricos sobre o assunto a ser estudado.

\section{A EVOLUÇÃO DO ESTADO}

A Origem do Estado é muito discutida por diversas teorias, sendo destacadas as teorias de origem familiar (cuja formação estava atrelada à estrutura familiar), as de origem da força (na qual a guerra e dominação são predominantes para a formação e estrutura dos Estados) e a teoria patrimonial (cujo fator econômico possuía relevância na construção do Estado) (DALLARI, 2012).

Nessas primeiras tipologias de Estado, porém, o papel do povo nas decisões políticas nem sempre era relevante, restringindo-se assim as decisões principalmente ao poder absoluto do chefe, atribuído em alguns casos às divindades. Com o passar do tempo, o descontentamento do povo para com a autoridade faz com que insurja a limitação dessa autoridade através da soberania do povo, devendo então, a parir daí, o exercício do poder limitar-se à demanda popular.

As primeiras formações de Estado, caracterizado como Estado Antigo, de natureza unitária, indivisível e com fortes aspectos religiosos, fundamentava sua formação estatal e o poder do líder nas influências divinas (DALLARI, 2012).

O Estado Grego e o Estado Romano se caracterizavam pelo primeiro vestígio do processo democrático, ainda que questionado por alguns autores devido à pequena proporção de membros da população que poderia exercer o direito de voto, contudo a vontade dessa parcela da sociedade era respeitada (DALLARI, 2012; MALUF, 2013). 
O Estado Medieval europeu, porém, não apresentava fatores de participação popular, sendo até a própria noção de Estado desfeita nesse período. Nessa época o direito particular sobressaía ao direito popular (AZAMBUJA, 2008).

Com o término do Estado Medieval e o objetivo de unificar as terras divididas pelo feudalismo, o Absolutismo Monárquico surge na Europa como um Estado com poder central forte, cujo monarca possuía poder absoluto sobre o Estado, justificados pelo desejo divino, predominando-se as ordens e vontades do Rei sobre a população (MALUF, 2013).

Todavia, a completa sujeição do Estado a poderes divinos suscitou uma reação antiabsolutista, o Liberalismo, defendendo a condução do Estado sob soberania do povo, cujos desejos deveriam prevalecer. Porém, percebe-se a absorção dos desejos do povo pelo Estado, sendo deficiente então na condução do bem comum (AZAMBUJA, 2008).

O Estado moderno surge, então, na queda do período monárquico. Os ideais de Rousseau de liberdade, fraternidade e igualdade favoreceram a revolução francesa, além de pregar o modelo de democracia, do Estado formado para todos (AZAMBUJA, 2008). Outros teóricos contratualistas, entre eles Locke e Hobbes, foram utilizados como bases para a formação das ideias de contratos sociais, que sucedem na formação de legislações dentro do Estado.

Com o passar do tempo e o desejo popular em contribuir com as decisões do Estado que se torna mais forte e instituído, o Estado Contemporâneo traz a ideia de um Estado planejador, que favoreça o desenvolvimento, expressando a soberania popular, resguardando os direitos humanos e institucionalizando processos democráticos na política, cujo grupo de representantes escolhidos pela população tem por objetivo tomar decisões conforme os desejos populares (MALUF, 2013; AZAMBUJA, 2008; DALLARI, 2012).

O Estado Democrático de Direito garante, através da Constituição Brasileira de 1988, uma estrutura constitucional específica para a consecução dos princípios políticos sociais e econômicos (BARRETO, 1996). Em outras palavras, consiste na representação democrática prevista na legislação do Estado. "Democracia significa que a 'vontade' representada na ordem jurídica é idêntica às vontades dos sujeitos." (KELSEN, 1998, p. 406).

O Estado Democrático de Direito, porém, para Bonavides (2001) não é um modelo de Estado ou de governo, mas de uma condição de confiança por parte do povo sobre os governantes, pautados na garantia constitucional dos direitos fundamentais.

Fernandes (2013) corrobora com Bonavides e complementa ao dizer que a limitação do Estado e do governo ocorre não pelo direito, mas pela subjugação à constituição. Ressalta ainda que:

A perspectiva assumida pelo direito caminha para a procedimentalização, e por isso mesmo, a
ideia de democracia não é ideal, mas configurando-se pela existência de procedimentos ao
longo de todo o processo decisório estatal, permitindo e sendo poroso à participação dos
atingidos, ou seja, da sociedade (FERNANDES, 2013 p. 288).

O Estado Democrático de Direito, para alguns autores, é a união de dois modelos: Estado de Direito e Estado Democrático, sendo o primeiro originário do modelo da Prússia (século XVIII), Rechtsstat, que frisava a impessoalidade do poder político, onde o Estado, e não o monarca, era quem possuía a soberania (FERNANDES, 2013; DALLARI, 2012). Já no Estado Democrático, cuja

Estudos do CEPE [ISSN 1982-6729]. Santa Cruz do Sul, n. 43, p.153-166, jan./jun. 2016. https://online.unisc.br/seer/index.php/cepe/index 
etimologia da palavra remete a um "governo do povo", surge em contraposição ao Estado Absoluto, em que o monarca possuía poder absoluto sobre o Estado (FERNANDES, 2013; DALLARI, 2012). Nesse novo modelo, o povo participa do processo de governo por democracia direta ou indireta, além de visar somente na escolha de atores políticos, mas na proteção da constitucionalidade pela superioridade da constituição, respeito aos direitos fundamentais e garantias jurídicas e processuais (FERNANDES, 2013; DALLARI, 2012).

No contexto apresentado, Maluf (2013) divide a democracia em duas formas distintas: Democracia Formal, que consiste em uma forma mais estrita de democracia, é o modelo de organização política, cuja soberania do povo está prescrita nas legislações vigentes, onde pressupõe os princípios de eletividade e temporariedade das funções legislativas e executivas; e a Democracia Substancial, que é um modelo mais amplo, onde, pela ordem constitucional, reconhece as garantias dos direitos fundamentais do homem.

Fernandes (2013) explica o papel do direito na democracia como um modelo organizador do povo, sendo a constituição o norteador de todo o processo de liberdade e igualdade, onde o direito garante à autonomia privada, e a democracia à autonomia pública, e a partir dessas autonomias, criam-se sistemas legislativos de ordem do povo.

Diante do exposto, pode-se afirmar que o Estado Democrático de Direito tem como objetivo dar proteção à soberania do povo, fundamentando a democracia sob o aspecto legal, tendo a constituição como a principal ferramenta de garantia democrática. Contudo, a participação popular no processo decisório da administração pública, além do controle e avaliação de políticas públicas, depende ainda de outros fatores, como poderá ser observado no capítulo 4.

\section{FEDERALISMO E A DEMOCRACIA NO BRASIL}

Sendo o Estado Federal compreendido como a união de organizações políticas autônomas (MALUF, 2013; FERNANDES, 2013), alguns autores defendem que o Estado federal é um modelo de Estado, não de governo, embora possua um relacionamento estreito entre essas duas concepções (DALLARI, 2012). Essa forma de Estado possibilita o processo de descentralização política e administrativa, bem como a aplicação do modelo de Estado Democrático de Direito.

A Federação é um modelo moderno, que surgiu com a experiência norte-americana em 1787 (FERNANDES, 2013). O contexto histórico norte-americano possibilitou a origem desse modelo de Estado, no qual as treze colônias tornaram-se independentes da Inglaterra e uniram-se para concentrar forças (DALLARI, 2012).

Contudo, a união das treze ex-colônias britânicas (entre 1781 e 1787), denominada de confederação, não foi suficiente para conseguirem controlar os problemas internos da confederação, necessitando de uma intervenção, a Convenção da Califórnia. Durante noventa dias, onde foram discutidos os problemas internos e, através da confecção da Constituição, buscou-se a solução desses problemas, bem como a manutenção da autonomia dos Estados-membros (MALUF, 2013).

Nesse sentido, o modelo federal norte-americano é denominado de federalismo centrípeto, no qual uma parcela do poder dos Estados-membros são entregues ao comando central. Dessa forma, o 
governo central torna-se possuidor apenas dos poderes que visam a ordem social e garantia de direitos fundamentais, ficando a maior parcela do poder sob a autonomia dos Estados-membros (FERNANDES, 2013). O modelo empregado pela constituição norte-americana realizou ainda a divisão dos poderes, baseados na obra "O Espírito das Leis" de Montesquieu, publicado em 1748, bem como o sistema de pesos e contrapesos nos poderes executivos, legislativos e judiciários, mantendo a igualdade entre os três poderes (DALLARI, 2012).

Observando o federalismo dos Estados Unidos, surgem outros modelos federalistas, como o brasileiro, com peculiaridades em relação ao modelo estadunidense, porém utilizando fundamentos similares. Com relação a esses fundamentos, o Quadro 1 apresenta algumas das principais características do federalismo apresentadas por Dallari (2012).

Quadro 1: Características fundamentais do federalismo

\begin{tabular}{|l|l|}
\hline \multicolumn{1}{|c|}{ CARACTERÍSTICA } & \multicolumn{1}{|c|}{ DESCRIÇÃO } \\
\hline União dos estados & $\begin{array}{l}\text { A união dos estados forma o estado federal, e } \\
\text { aqueles recebem a característica de estado-membro. }\end{array}$ \\
\hline Base jurídica é a constituição & $\begin{array}{l}\text { Todos os assuntos que possam interessar os } \\
\text { estados-membros são expressos numa constituição. }\end{array}$ \\
\hline Não há direito de secessão & $\begin{array}{l}\text { Uma vez instituída o estado federal, nenhum estado- } \\
\text { membro poderá desfazer do acordo, mesmo quando } \\
\text { não está expresso na constituição. }\end{array}$ \\
\hline Soberania pertence ao estado federal & $\begin{array}{l}\text { Apesar de cada estado-membro ser autônomo, } \\
\text { apenas o estado federal é soberano. Ressalta-se a } \\
\text { impossível coexistência de mais de uma soberania } \\
\text { em um estado. }\end{array}$ \\
\hline $\begin{array}{l}\text { Atribuições da União e membros federados } \\
\text { expressos na constituição }\end{array}$ & $\begin{array}{l}\text { Constituição prevê as competências de cada membro } \\
\text { integrante da federação. }\end{array}$ \\
\hline Autonomia dos estados-membros & $\begin{array}{l}\text { A cada esfera de competência se atribui renda } \\
\text { própria, tornando viável a autonomia dos entes. }\end{array}$ \\
\hline $\begin{array}{l}\text { Poder político compartilhado entre união e } \\
\text { unidades federadas }\end{array}$ & $\begin{array}{l}\text { Casas legislativas representantes do povo dos } \\
\text { estados-membros; autonomia política dos estados- } \\
\text { membros. }\end{array}$ \\
\hline Fonte: Elaborado pelos autores com base em Dallari (2012). \\
\hline
\end{tabular}

Antes de adentrar no modelo federativo brasileiro especificamente, é importante proceder a uma breve análise histórica que demonstre os ciclos de diferentes "federalismos" ao longo do século $X X$ vividos no Brasil, nos quais descentralização e autonomia não andavam juntos necessariamente (SOUZA, 2006).

O primeiro momento a se destacar das subdivisões do território nacional é a colonização portuguesa e a divisão do território em capitanias hereditárias que, mais tarde, com a Constituição de

Estudos do CEPE [ISSN 1982-6729]. Santa Cruz do Sul, n. 43, p.153-166, jan./jun. 2016. https://online.unisc.br/seer/index.php/cepe/index 
1824, promulgada por D. Pedro I, são transformadas em províncias subordinadas ao poder central (COSTA, 2008).

Dois anos após a proclamação da República em 1889, é promulgada a Constituição da República dos Estados Unidos do Brasil de 1891, que consagrou o Brasil enquanto Estado republicano, instituindo o federalismo (transformação das províncias em Estados) e inaugurando o regime presidencialista, marcando então a transição da monarquia para a república (COSTA, 2008).

Em 1937, por meio de um golpe de Estado, Getúlio Vargas promulga a Constituição de 1937, dando origem ao Estado Novo, e marcando assim a reinstalação de um Estado unitário, com forte caráter autoritário e centralizada na figura do presidente da República (COSTA, 2008).

Apenas com a Constituição de 1946, com o fim do Estado Novo, é restabelecido o federalismo, o estado de direito e as garantias individuais, restaurando-se assim a divisão de poderes e devolvendo a autonomia aos estados (COSTA, 2008; SOUZA, 2006).

A Constituição de 1967 no período militar (1964-1985) marca novamente a maior centralização do poder, enfraquecendo e descaracterizando o princípio federativo (SANTOS; RIBEIRO, 1993).

Por fim, com a Constituição de 1988, que traz importantes alterações na natureza das relações federativas, são ampliados os mecanismos de inclusão política e participação, estabelecendo larga faixa de intervenção do Estado no domínio econômico, redistribuindo os ingressos públicos entre as esferas de governo e institucionalizando-se os instrumentos de política social, rendendo avanços no que concerne à democratização da esfera pública (COSTA, 2008).

Apesar do modelo centralizador no qual se fundou o federalismo brasileiro, a Constituição Federal de 1988, marcando a transição democrática, é considerada um marco da descentralização federativa. A partir dessa data os municípios passam a ser considerados como unidades federadas, marcando também a distribuição de competências aos municípios, com o intuito de propiciar maior autonomia e poder aos organismos de administração pública local. A atual Constituição, assim, apresenta significativos avanços na descentralização político-administrativa e no aperfeiçoamento do pacto federativo-nacional (PEPPE et al., 1997).

A transferência do poder decisório (descentralização) aos municípios, expressa relevância às estruturas do poder local, uma vez que implica, por um lado, em responsabilidade e participação na estrutura do poder local, por outro, em processos de modernização gerencial da gestão pública (KERBAUY, 2001), permitindo não apenas aos entes federados a capacidade de implementação e custeio de políticas, mas também ao processo político local estratégias de formulação e supervisão das políticas públicas, bem como do apoio estadual e mobilização popular organizada (PEPPE et al., 1997).

Quanto à origem da federação no Brasil, há de se destacar que se difere da maioria dos demais Estados Federais conhecidos. Ao invés de nascer da união voluntária das partes, nessa forma de origem do federalismo brasileiro, chamada de modelo centrífugo, o Estado centralizador tipicamente distribui parte do poder aos Estados-Membros, continuando com grande parte do poder e tornando os Estados-membros fortemente dependentes do poder central (FERNANDES, 2013).

4. Participação popular: o papel do povo nos processos decisórios 
Para se iniciar o debate acerca da participação popular, é importante que se retome em sua base: a democracia. As primeiras conceituações de democracia remontam do modelo de Aristóteles, cuja democracia ocorria quando homens livres e pobres governavam o Estado (ARISTÓTELES, 2006). Para Aristóteles (2006), cidadão era apenas homens natos da localidade e livres, excluindo estrangeiros, escravos, mulheres e crianças.

Hoje, entende-se como democracia a forma de exercício da ação governativa na qual as decisões são baseadas na vontade soberana do povo, seja de forma direta ou indireta, sendo então o próprio povo titular e objeto do poder legítimo (BONAVIDES, 1993 apud CARNEIRO, 2007). De acordo com Carneiro (2007) essa noção de democracia tomada por Bonavides (1993) está profundamente ligada à soberania popular. Para Bonavides (1996) a democracia ainda é tratada como sendo um direito um direito fundamental, comparando-a aos direitos de igualdade, liberdade e fraternidade.

O poder democrático, de acordo com Silva (2005), pode ser exercido de forma direta, aquela na qual o povo exerce diretamente os poderes governamentais, fazendo leis, administrando e julgando; ou pela democracia indireta, conhecida por democracia representativa, é aquela na qual o povo, fonte do poder, cede a seus representantes eleitos as funções de governo (SILVA, 2005). Há autores que consideram ainda uma terceira forma de exercício de democracia, um sistema misto, intitulada semidireta.

No Brasil, regido sob a "forma republicana, sistema representativo e regime democrático" (BRASIL, 1988), de acordo com Bonavides (1993 apud CARNEIRO, 2007) a democracia representativa enfrentava no início dos anos 1990 uma crise, o que implicaria numa possível ruptura entre Estado e sociedade. O autor argumenta então que a "solução" para esta situação seria a instalação de uma democracia participativa que se fundamente sobretudo no princípio da soberania popular, contando então com instrumentos para o exercício da vontade da sociedade de forma democrática, instaurando-se assim um novo sistema.

É assim que, a partir da década de 1990, com alicerce na Constituição Federal de 1988, que ofereceu à sociedade maior oportunidade de participação em assuntos de interesse público, alguns governos locais começaram a trabalhar iniciativas que incentivariam a participação, começando então a se abrir espaço para intervenção popular na agenda pública.

Dessa forma, baseados na importância da participação social surgem mecanismos como os conselhos gestores e o orçamento participativo, marcando assim uma nova Era na relação entre Estado e sociedade, instituindo então âmbitos de participação popular na esfera pública.

Parece nascer assim uma nova ordem na gestão pública e na democracia brasileira, dotada agora de instrumentos de participação popular, caminhando para uma dinâmica mais participativa e argumentativa, estabelecendo assim as condições para o surgimento da democracia deliberativa.

É importante destacar que, são encontradas na literatura diferenciações entre democracia participativa e democracia deliberativa. Tomando a concepção trazida por Oliveira et al (2010), considera-se que o termo democracia participativa se refere àquela forma em que os tipos elitistas de representação são superados sem, contudo, concretizar o ideal deliberativo; ao passo que na 
democracia deliberativa, sendo um modelo "superior", a solução dos problemas advêm diretamente dos cidadãos (OLIVEIRA et al, 2010).

Ainda que alguns autores, a exemplo de Bresser-Pereira (2005), considerem o termo democracia deliberativa ambicioso demais para as condições da participação popular vivenciadas no Brasil atualmente, tomar-se-á, para fins deste trabalho, o que apresenta Avritzer (2000) quando defende que "o local da democracia deliberativa deve ser os fóruns entre Estado e sociedade [...] no caso brasileiro, os conselhos e o orçamento participativo" (AVRITZER, 2000, p.43). Destaca-se ainda que "apesar de participação e deliberação não serem sinônimos, parece interessante o fato de todos os arranjos deliberativos se constituírem em formas ampliadas de participação" (AVRITZER, 2000, p.43). Em relação a essas denominações, busca-se apresentar com o Quadro 2 as diferentes perspectivas sobre o termo. Dessa forma, para fins das análises aqui constantes, deverá se considerar os orçamentos participativos enquanto instrumentos de participação popular e por sua vez, da democracia deliberativa.

Ao analisar o processo de instauração da participação popular, Kerbauy (2001) aponta que deve ser feita uma ressalva:

\begin{abstract}
Apesar do processo de descentralização vir acompanhado de um forte enfoque participativo contemplado pela Constituição de 1988 e acentuado pela Lei Orgânica Municipal, promulgada em 1991[...] essa questão não está colocada ainda claramente para o poder local, que tem encontrado muitas dificuldades em adequar modelos participativos e modelos de gestão pública (KERBAUY, 2001, p. 56).
\end{abstract}

Quadro 2: Democracia deliberativa e democracia participativa

\begin{tabular}{|c|c|c|c|c|}
\hline Modelo & Descrição & Precursores & Ideais & Críticas \\
\hline $\begin{array}{l}\text { Democracia } \\
\text { deliberativa }\end{array}$ & $\begin{array}{c}\text { Modelo o qual } \\
\text { possibilita a } \\
\text { socialização de } \\
\text { informações e o } \\
\text { pluralismo social. } \\
\text { Considera-se } \\
\text { fatores como o } \\
\text { argumento e o } \\
\text { consenso nas } \\
\text { tomadas de } \\
\text { decisões }\end{array}$ & $\begin{array}{c}\text { Habermas } \\
\text { Raws } \\
\text { Joshua Cohen. }\end{array}$ & $\begin{array}{c}\text { Liberal- } \\
\text { social }\end{array}$ & $\begin{array}{l}\text { Modelo distante de se } \\
\text { alcançar. Processo } \\
\text { ideológico de } \\
\text { formação de } \\
\text { democracia. } \\
\text { Weber (1946, apud } \\
\text { Avritzer, 2000) } \\
\text { questiona quanto à } \\
\text { pluralidade e conflitos } \\
\text { culturais não gerar o } \\
\text { consenso. } \\
\text { Shumpeter (1942, } \\
\text { apud Avritzer, 2000) } \\
\text { dizia que as vontades } \\
\text { individuais eram } \\
\text { impulsos, o que } \\
\text { dificultaria a } \\
\text { democracia. }\end{array}$ \\
\hline $\begin{array}{l}\text { Democracia } \\
\text { participativa }\end{array}$ & $\begin{array}{l}\text { Modelo o qual } \\
\text { precede da } \\
\text { participação }\end{array}$ & $\begin{array}{l}\text { Nasce do modelo } \\
\text { teórico de } \\
\text { Aristóteles, Cícero, }\end{array}$ & $\begin{array}{l}\text { Liberal } \\
\text { clássico }\end{array}$ & $\begin{array}{l}\text { Modelos participativos } \\
\text { não visam a eficiência } \\
\text { da administração }\end{array}$ \\
\hline
\end{tabular}

Estudos do CEPE [ISSN 1982-6729]. Santa Cruz do Sul, n. 43, p. 137-150, jan./jun. 2016. https://online.unisc.br/seer/index.php/cepe/index 


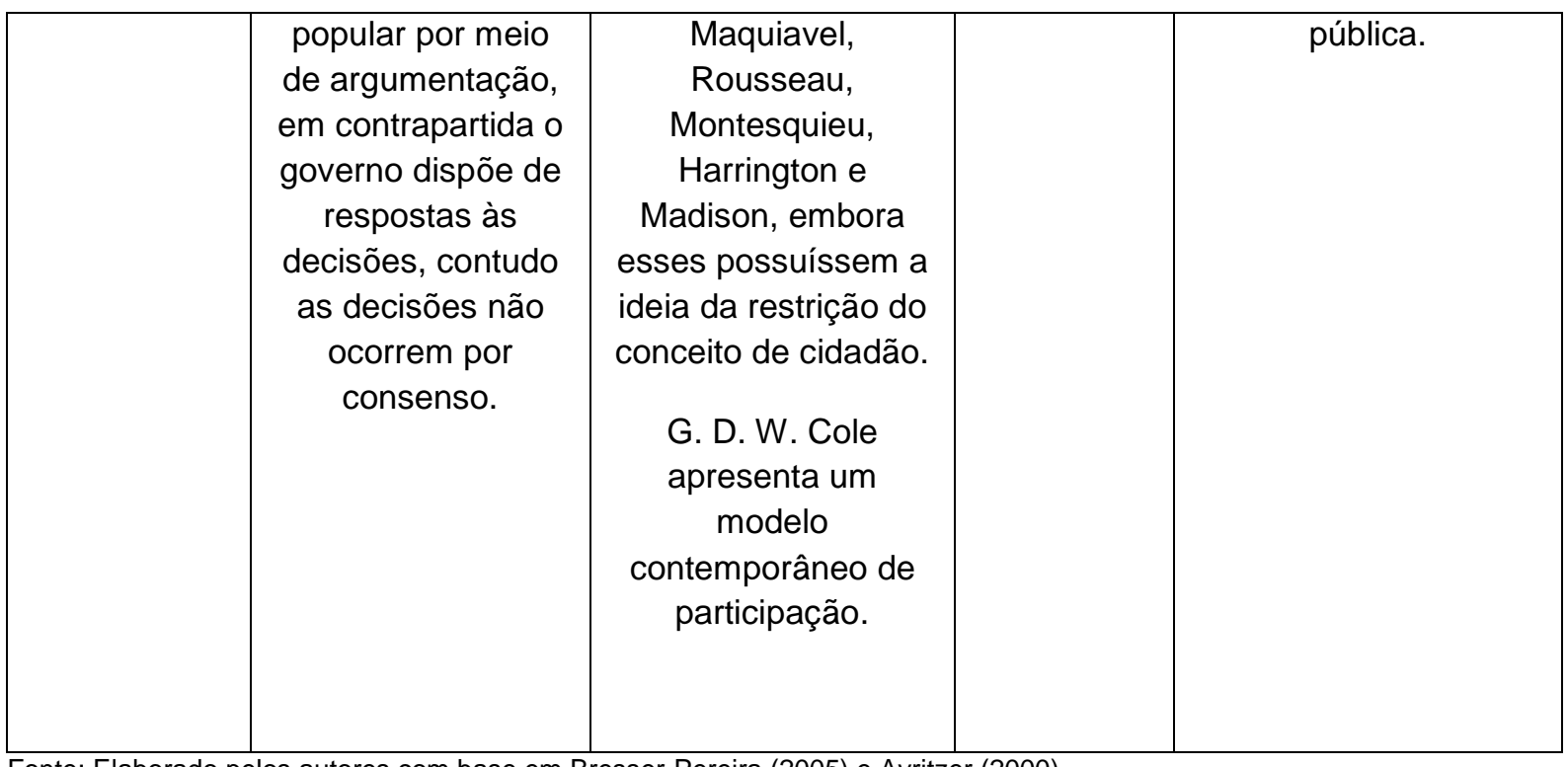

Fonte: Elaborado pelos autores com base em Bresser-Pereira (2005) e Avritzer (2000).

Pode-se ainda destacar algumas formas de interpretar a participação. A primeira delas é entender a participação como um modo de transformar os indivíduos desorganizados em membros da sociedade civil, com potencial para intervirem naqueles aspectos que os afetem. Uma segunda forma de ver a participação seria pela ótica do empoderamento dos pobres, de modo a fazer com que eles tomem consciência política e sejam capazes de reformar os sistemas político e social pela via da ação coletiva (SOUZA, 2001).

De acordo com Tocqueville (2005 apud CARNEIRO, 2007), a soberania popular é verídica quando a administração se sujeita ao poder e à vontade popular, da qual emana. $\mathrm{O}$ autor ainda argumenta que um dos princípios constitutivos da ordem social democrática é a igualdade de condições, assim, não há verdadeira democracia sem igualdade de condições.

É importante ressaltar que, apesar de haver no Brasil, contextos socioeconômicos e traços da cultura brasileira que, a princípio, parecem influir de forma negativa na participação popular, tais como o clientelismo, elitismo, problemas locais (de habitação, educação, saúde, transporte), individualismo e desequilíbrio na distribuição de recursos (SOUZA, 2001), a própria participação da sociedade civil nos negócios públicos tendem a representar ainda potenciais meios para minimização do patrimonialismo e do clientelismo político (KERBAUY, 2001).

Num país como o Brasil, historicamente marcado pela exclusão de grupos menos favorecidos, alternativas que propiciem a participação da sociedade civil na formulação da agenda pública e o acesso desses ao processo decisório, são iniciativas inovadoras e que têm muito a contribuir com a administração pública brasileira.

Por fim, pode-se afirmar que, a descentralização entendida aqui pelos termos de Kerbauy (2001), como transferência do processo decisório ao poder local, associada à participação popular, possui enorme potencial para atuar como um corretivo da democracia representativa e a processos de modernização gerencial da gestão pública.

A ver como modernização desse processo gerencial, um dos mecanismos do engajamento do cidadão nos processos decisórios dentro do modelo de federalismo brasileiro é o orçamento 
participativo. Nesse sentido, esse artigo avança para além de descrever o contexto histórico e empírico dessa matéria, ilustrando uma experiência concreta de participação social.

\section{NOVOS ARRANJOS DELIBERATIVOS: O ORÇAMENTO PARTICIPATIVO}

Ao lado dos conselhos gestores, o orçamento participativo tem sido considerado um dos atores-chave da democracia deliberativa no Brasil (AVRITZER, 2000). Trata-se de um mecanismo de participação popular em que se propõe a articulação entre a democracia representativa e participativa, através da concessão da soberania por aqueles que a detêm pelo processo representativo, da incorporação de instrumentos de participação, regendo-se pelo princípio da autorregulação soberana e caracterizando-se pelo intento de reversão das prioridades de distribuição de recursos públicos localmente (AVRITZER, 2003).

Com notável crescimento da presença do orçamento participativo no Brasil, entre 1997 e 2000, existiram 140 administrações municipais que adotaram o orçamento participativo, sendo a maioria (127) em cidades de até 500 mil habitantes (CARLOS, 2015). Em 2014 foram contabilizado aproximadamente 300 casos de Orçamento Participativo no Brasil (IPEA, 2014).

É importante destacar que no Brasil, como nos aponta Souza (2001), alguns fatores precederam e propiciaram experiências de participação popular a exemplo do orçamento participativo, como algumas experiências nesse sentido anteriores à redemocratização do Brasil, o aumento dos recursos municipais como resultado da redemocratização e a multiplicação dos partidos de esquerda na administração local.

Por se tratar de um país com fortes traços de desigualdade no acesso ao processo decisório, o orçamento participativo tem sido um dos únicos mecanismos com capacidade de transformar os investimentos públicos de favores políticos em direitos, diminuindo também esse desequilíbrio no poder decisório (SOUZA, 2001).

O orçamento participativo pode ser considerado um processo bem sucedido de fortalecimento da democracia local, mas ainda não pode ser considerado uma forma de democratização de políticas públicas, uma vez que, para isso, deve estender sua abrangência territorial (AVRITZER, 2003).

De acordo com Souza (2001), embora o orçamento participativo não atinja as demandas daquela população em extrema pobreza, vem suprindo a negligência das administrações locais anteriores em relação às péssimas condições de infraestrutura das áreas de baixa renda. Além disso, observou-se que o orçamento participativo foi eficaz no sentido de propiciar que os grupos socialmente excluídos pudessem influenciar na alocação de recursos e ampliar o acesso desses aos serviços urbanos básicos (SOUZA, 2001).

O orçamento participativo, enquanto espaço de participação, pode ser entendido sob o aspecto de uma concepção distributiva da democracia, sendo caracterizado pela igualdade no direito de participação; pela alocação de recursos de investimentos baseados em critérios objetivos; e por dirigir a participação com base numa combinação de regras de democracia direta e representativa (SANTOS, 1998 apud AVRITZER, 2003, p. 9). 
Nesse sentido, pode-se afirmar que o orçamento participativo tem propiciado um incremento na democracia local, uma vez que possibilita que participem do processo decisório representantes de segmentos menos favorecidos que, normalmente, não teriam acesso a essa instância; por outro lado, deve-se destacar o enfraquecimento do poder legislativo sob a sombra da participação social (SOUZA, 2001).

Por fim, considera-se que o orçamento participativo tem sido uma forma de reinvenção da democracia local com foco na formação de sinergia entre Estado e sociedade civil, levando não só ao empoderamento desta, mas também ao controle por parte dos participantes sobre o processo de tomada de decisão (ABERS, 2000 apud AVRITZER, 2003, p. 9).

As bases teóricas do Orçamento Participativo remetem às concepções de democracia participativa ou deliberativa (vide tópico 4) e remete à participação popular na gestão pública. A primeira experiência orçamento participativo remete à cidade de Pelotas, no Rio Grande do Sul, sendo depois encaminhado para Porto Alegre (BALESTERO, 2011). Posteriormente, diversos outros municípios incorporaram tal experiência à gestão municipal.

Segundo Balestero (2011) a experiência de orçamento participativo em Porto Alegre remete a algumas dificuldades iniciais como a crise financeira municipal na época, impossibilitando que muitas obras discutidas fossem realmente efetivadas pelo poder público, gerando descrédito por parte da população. Ainda assim, enfrentados os desafios, posteriormente, os Orçamentos Participativos possibilitaram uma reforma tributária para obtenção de recursos destinados às políticas públicas; uma reestruturação interna da administração; uma nova divisão de regiões da cidade baseada em critério sócio territorial; a substituição da lógica da concentração dos investimentos ela distribuição por setores, de maneira a reformular os critérios de distribuição dos recursos; a instituição dos Conselhos de Orçamentos Participativos, conselhos e assembleias regionais (BALESTERO, 2011).

\section{CONCLUSÃO}

Este estudo sintetizou e debateu a participação popular motivada pelo modelo federalista, passando pela evolução histórica do estado, o Estado Federal e o federalismo e democracia no Brasil.

Como demonstrado, com a evolução do Estado até o Estado Democrático de Direito, possibilita-se e prevê-se que os representantes ajam em nome do interesse coletivo, garantindo assim a consecução do bem público. O modelo federativo, enquanto possibilitador do processo de descentralização político-administrativa, sob as análises deste trabalho, tende a manifestar-se como uma potencialidade na concretização da participação popular.

O Brasil, com herança dos modelos autocráticos advindos da monarquia e dos períodos ditatoriais, possui fortes traços de desigualdade no acesso ao processo decisório. Associa-se a isso o fato histórico da centralização do poder no governo central, com baixa, ou nenhuma, autonomia dos municípios e dos Estados para garantir as necessidades locais.

O modelo democrático adotado no Brasil após a constituição de 1988, bem como a descentralização político-administrativa possibilita que o povo participe das decisões do governo,

Estudos do CEPE [ISSN 1982-6729]. Santa Cruz do Sul, n. 43, p.153-166, jan./jun. 2016. https://online.unisc.br/seer/index.php/cepe/index 
assim como o controle e aplicação de políticas públicas mais aderentes às necessidades da população local.

Destaca-se o orçamento participativo, que tem se mostrado um importante instrumento de diminuição dessa desigualdade, uma vez que trabalha com a visão de tornar concretas as necessidades populares, diminuindo dessa forma o desequilíbrio no poder decisório.

Porém, conforme discutido no capítulo 5, o orçamento participativo, ainda que esteja se firmando como um mecanismo potencial de participação social e de fortalecimento da descentralização político-administrativa, não atingiu a plenitude do seu objetivo de democratização de políticas públicas, sendo necessário para isso o seu fortalecimento no âmbito nacional.

Por fim, retomando o questionamento inicial, verifica-se que o federalismo, se formando pela descentralização político-administrativa e possuindo como traço a democracia prevista na constituição, tem-se tornado um mecanismo de garantias da participação popular. Contudo, a efetiva participação ainda depende de instrumentos, como o orçamento participativo, que viabilizem o acesso do povo às decisões e ao processo de formulação e controle de políticas públicas.

\section{REFERÊNCIAS}

ARISTÓTELES. Política. Tradução de Roberto Leal Ferreira. 3ª̣ed., São Paulo: Martins Fontes, 2006.

AVRITZER, L. O orçamento participativo e a teoria democrática. In: A inovação democrática no Brasil: o orçamento participativo. São Paulo: Cortez, 2003, p. 13-60. Disponível em: < https://www.ces.uc.pt/curso-op/materiais/14_leonardo_avritzer.pdf>. Acesso em: 16 mai. 2015.

AVRITZER, L. Teoria Democrática e deliberação pública. Lua Nova, n. 50, p. 25-46, 2000.

BALESTERO, Gabriela Soares. Orçamentos Participativos como Instrumento de Participação Popular na Efetivação das Políticas Públicas. Braz. J. Int'I L., v. 8, p. 45, 2011.

BARRETTO, V. Interpretação constitucional e Estado democrático de direito. Revista de direito público. Rio de Janeiro, v. 203, mar. 1996. p 11-23.

BONAVIDES, P. Curso de direito constitucional. 6. ed. São Paulo: Malheiros, 1996.

BONAVIDES, P. Teoria constitucional da democracia participativa: por um Direito Constitucional de luta e resistência, por uma Nova Hermenêutica, por uma nepolitização da legitimidade. São Paulo: Malheiros, 2001.

BRASIL, Senado Federal. Constituição da República Federativa do Brasil. Brasília: 1988.

BRESSER PEREIRA, L. C. Democracia republicana e participativa. Novos estudos CEBRAP, São Paulo, v.71, p-77-91, 2005.

CARLOS, E. Controle social e política redistribuitiva no orçamento participativo. Vitória: EDUFES, 2015. 221 p. Disponível em:

<http://repositorio.ufes.br/bitstream/10/1264/6/Livro\%20Edufes\%20Controle\%20Social\%20e\%20pol\% C3\%ADtica\%20redistributiva\%20no\%20or\%C3\%A7amento\%20participativo.pdf>. Acesso em 16. mai. 2015.

CARNEIRO, R. M. de M. Teoria da democracia participativa: análise à luz do princípio da soberania popular. Revista Jurídica, Brasília, v. 9, n. 87, p.25-34, out/nov 2007. Disponível em: 
$<$ http://www.planalto.gov.br/ccivil_03/revista/rev_87/Artigos/PDF/RommelMadeiro_rev87.pdf>. Acesso em: 16 mai. 2015.

COSTA, G. P. Heranças patrimonialistas, disfunções burocráticas, práticas gerenciais e os novos arranjos do estado em rede: entendendo a configuração atual da administração pública brasileira. 2012. 256p. Tese (Doutorado em Administração) - Fundação Getulio Vargas (FGV), Rio de Janeiro, 2012.

COSTA, F. L da. Brasil: 200 anos de Estado; 200 anos de administração pública; 200 anos de reforma. Revista de Administração Pública. Rio de Janeiro: 42(5):829-74, SET/OUT. 2008.

DALLARI, D. de A.. Elementos de teoria geral do Estado. 31. ed. São Paulo: Saraiva, 2012.

FERNANDES, B. G. Curso de direito constitucional. 5. ed. Salvador: Editora Juspodivm, 2013.

IPEA. Participação em Foco. Continuidade de programas de orçamento participativo é mais frequente no Sudeste, 2014. Disponível em: <http://www.ipea.gov.br/participacao/noticias-doipea/981-op-mds>. Acesso em: 16 jul. 2016.

KELSEN, H. Teoria geral do direito e do Estado. 3. ed. São Paulo: Martins Fontes, 1998.

KERBAUY, M. T. M. Federalismo, descentralização e democracia. Estudos de Sociologia, v. 6, n. 10, 2001. Disponível em: <http://seer.fclar.unesp.br/estudos/article/view/180/177>. Acesso em: 18 mai. 2015.

LOPES, B. de J.; SILVA, E. A.; FERREIRA, M. A. M.; EMMENDOERFER, M. L.. A Institucionalização da Participação Cívica nos Conselhos Gestores de Saúde: uma análise do espaço deliberativo e de sua ocupação. In: Anais do VII Encontro Nacional de Pesquisadores em Gestão Social, 2013, Belém-PA, 2013. Disponível em: <http://www.anaisenapegs.com.br/2013/dmdocuments/1647.pdf>. Acesso em 25 mai. 2015.

MALUF, S. Teoria Geral do Estado. 31 ed. São Paulo: Saraiva, 2013.

PEPPE, A. M.; PEREIRA, E. da S.; BRITO, F. R. C. D.; MACEDO, M. E. Reflexões sobre a Federação Brasileira. Revista de Administração Pública. Rio de Janeiro, v. 41, n. 4, ago. 1997. Disponível em: <http://bibliotecadigital.fgv.br/ojs/index.php/rap/article/viewFile/7885/6553>. Acesso em: 01 jun. 2015.

SANTOS, R. S.; RIBEIRO, E. M.. A Administração política brasileira. Revista de Administração Pública, v. 27, n. 04, 1993. Disponível em:

<http://bibliotecadigital.fgv.br/ojs/index.php/rap/article/view/8553/7292>. Acesso em: 03 jun. 2015.

OLIVEIRA, V. C. da S. et al. Os conselhos gestores municipais como instrumentos da democracia deliberativa no Brasil. Cad. EBAPE.BR, Rio de Janeiro, v. 8, n. 3, p. 422-437, Sept. 2010

. Disponível em: <http://www.scielo.br/scielo.php?script=sci_arttext\&pid=S1679-

39512010000300004>. Acesso em: 01 Jun 2015.

SILVA, J. A. da. Curso de direito constitucional positivo. São Paulo: Malheiros, 2005

SOUZA, C.. Construção e consolidação de instituições democráticas: papel do orçamento participativo. São Paulo em perspectiva, v. 15, n. 4, p. 84-97, 2001. Disponível em:

<http://www.scielo.br/scielo.php?pid=S0102-88392001000400010\&script=sci_arttext\&tlng=es>. Acesso em: 16 mai. 2015.

SOUZA, M. do C. C. de. Federalismo no Brasil: aspectos político-institucionais (1930-1964). Rev. bras. Ci. Soc., São Paulo, v. 21, n. 61, p. 7-40, 2006. Disponível em < http://www.scielo.br/scielo.php?pid=S0102-69092006000200002\&script=sci_arttext>. Acesso em: 01 Jun 2015. 